\title{
Topical and prospective processes of acetoxylation
}

\author{
Grzegorz Lewandowski, Marcin Bartkowiak*, Eugeniusz Milchert \\ West Pomeranian University of Technology, Szczecin, Institute of Chemical Organic Technology, 70-322 Szczecin, \\ ul. Putaskiego 10, Poland \\ "Corresponding author: E-mail adress: marcin.bartkowiak@zut.edu.pl
}

\begin{abstract}
The latest acetoxylation processes have been described in this work: oxidative acetoxylation of propene to allyl acetate, acetoxylation of propene to propene glycol and its acetates, acetoxylation of methyl tert-butyl ether and oxidative acetoxylation of cyclohexene by hydrogen peroxide. Acetoxylation of 1,3-butadiene, isobutene and toluene were presented together with a short description of the acetoxylation catalysts.
\end{abstract}

Keywords: acetoxylation, allyl acetate, hydrogen peroxide, propene glycol monoacetate, tert-butyl acetate, 2-cyclohexenyl acetate, tetrahydrofuran, benzyl acetate.

\section{INTRODUCTION}

Acetoxylation is one of the industrial esterification processes and it is the most frequently used due to a large number of applications of the acetates obtained in this process. Acetoxylation is usually processed in the classic way: the reaction between acetic acid or acetic anhydride and appropriate alcohol. Acetoxylation of ethylene and acetylene have the industrial relevance, too.

Processes of acetoxylation have been known for many years and used in the production of valuable intermediates in chemical industry. These processes found application as the competitive methods of the production of many chemicals and they replaced many older methods, which were more undesirable for the environment.

The most intensively developed acetoxylation techniques were described in this work, especially the latest ones and the most promising for the chemical technology.

An example of using acetoxylation as cleaner technology is the method of the production of allyl alcohol and glycerol epichlorohydrin, developed and introduced into industry around 20 years ago.

\section{THE PROCESSES OF ACETOXYLATION}

\section{Oxidative acetoxylation of propene to allyl alcohol}

This process was developed and introduced into industry in 1985 by Showa-Denko K.K. Corporation. The process consists of two stages: oxidative acetoxylation of propene to obtain allyl acetate and then the hydrolysis of the previously formed acetate to allyl alcohol. These stages can be described by the following reaction equations $\mathbf{1 , 2 , 3}$ : support. The temperature of the process is $160-180^{\circ} \mathrm{C}$, the pressure in the reactor is $0.49-0.98 \mathrm{MPa}^{4,5}$.

A simplified technological scheme of oxidative acetoxylation of propene and hydrolysis of the formed allyl acetate to allyl alcohol was shown in Fig.1. Propene, acetic acid, oxygen and recycle gas are introduced to heater (2), mounted before acetoxylation reactor (1). The postreaction gaseous mixture is cooled in condenser (3) to condense the liquid compounds such as allyl acetate, water and acetic acid.

This mixture is separated into two phases: liquid and gaseous in separator (4). The gaseous phase contains unreacted propene and oxygen as well as carbon dioxide. After removing $\mathrm{CO}_{2}$ in absorber (5) the gaseous mixture is recycled to the reactor. The liquid phase from separator (4) is collected in reservoir (7) and contains mainly allyl acetate and acetic acid. The liquid phase can be distilled to obtain pure allyl acetate and acetic acid.

The next step is the process of hydrolysis of allyl acetate to allyl alcohol. The hydrolysis is carried out in the liquid phase in acidic environment. It can be processed in the presence of sulfuric acid. The best results can be achieved using strongly acidic cationite as Dowex 50x8 or Amberlyst IRA in the form of immobilized bed as well as at the temperature of $85-95^{\circ} \mathrm{C}$ with the molar ratio of water to allyl acetate $1.5-5: 1$.

A reactor in the form of reaction and distillation column or a cascade of semibatch reactors with ideal mixing can be used in industrial applications. A decreased molar ratio of water/allyl acetate $=1.5: 1$ can be used in the mentioned column method. Allyl acetate conversion is 98 mol\% with the selectivity of transformation to allyl alco-

$$
\begin{aligned}
& \mathrm{CH}_{2}=\mathrm{CH}-\mathrm{CH}_{3}+\mathrm{CH}_{3} \mathrm{COOH}+0.5 \mathrm{O}_{2}-\stackrel{P d}{\longrightarrow} \mathrm{CH}_{2}=\mathrm{CH}-\mathrm{CH}_{2} \mathrm{OCOCH}_{3}+\mathrm{H}_{2} \mathrm{O} \\
& \mathrm{CH}_{2}=\mathrm{CH}-\mathrm{CH}_{2} \mathrm{OCOCH}_{3}+\mathrm{H}_{2} \mathrm{O} \stackrel{\mathrm{H}^{+}}{\rightleftharpoons} \mathrm{CH}_{2}=\mathrm{CH}-\mathrm{CH}_{2} \mathrm{OH}+\mathrm{CH}_{3} \mathrm{COOH}
\end{aligned}
$$

Summary:

$$
\mathrm{CH}_{2}=\mathrm{CH}-\mathrm{CH}_{3}+0.5 \mathrm{O}_{2} \longrightarrow \mathrm{CH}_{2}=\mathrm{CH}-\mathrm{CH}_{2} \mathrm{OH}
$$

Oxidative acetoxylation of propene to allyl acetate is the first step of epichlorohydrin production process. Acetoxylation is performed in the gaseous phase in the presence of metallic palladium catalyst deposited on a hol equal to $100 \mathrm{~mol} \%$. Lower conversion of allyl acetate can be achieved using the cascade of reactors with the same selectivity of transformation to allyl alcohol. 


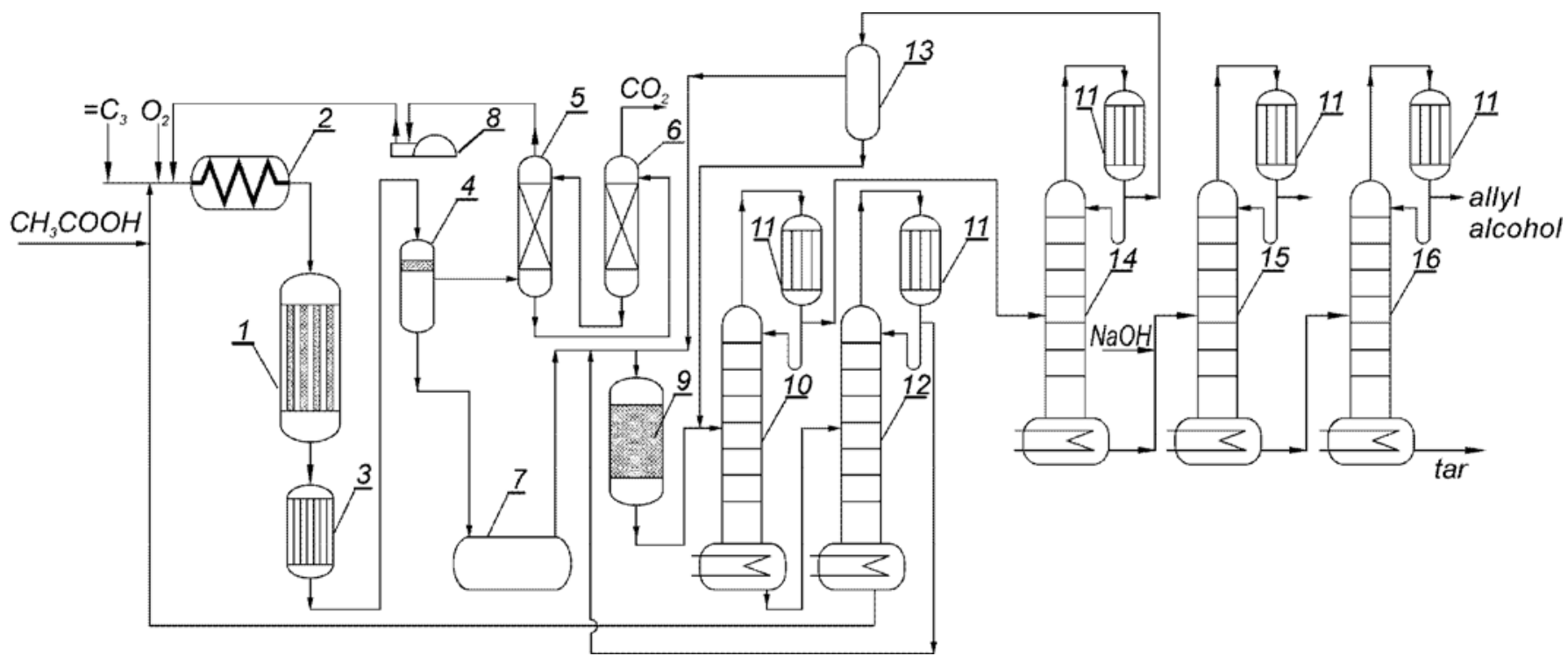

Figure 1. A technological scheme of allyl alcohol production using allyl acetate as the intermediate.

1 - acetoxylation reactor, 2 - raw materials heater, 3 - condenser, 4 - phase separator, $5-\mathrm{CO}_{2}$ absorber, 6 - desorber, 7 - tank, 8 - compressor, 9 - allyl acetate hydrolysis reactor, 10,12,14,15,16 - distillation columns, 11 - reflux condenser

The post-reaction mixture from the hydrolysis reactor (9) is conducted to the distillation column (10), where the mixture of allyl alcohol, water and allyl acetate (as the three-compound azeotrope) is distilled off. The tail fraction consists of water and acetic acid. After the separation of the tail fraction on column (12), water and acetic acid are recycled to the hydrolysis reactor and the acetoxylation reactor, respectively.

The distillate from column (10) is conducted to the rectifying column (14) where allyl acetate together with a part of allyl alcohol and water are distilled off. The water solution of allyl acetate is separated off in the phase separator and recycled to the hydrolysis reactor (9), when the water solution of allyl alcohol from the separator is recycled to the distillation column (10). The raw allyl alcohol remains in the tail fraction from column (14). In the next step natrium hydroxide is conducted to the tail fraction to remove impurities: small amounts of allyl acetate and acetic acid.

Two rectifying columns (15 and 16) are used to distill off hydrated allyl alcohol and pure anhydrous allyl alcohol, respectively. The tail fraction contains tars as the result of decomposition and polymerization of the final products.

Hydrolysis of allyl acetate to allyl alcohol with oxidative acetoxylation of propene to allyl acetate can be numbered among waste-free processes. Acetic acid from acetate hydrolysis is used again in acetoxylation step and water from acetoxylation is recycled to hydrolysis. Thus allyl alcohol is produced from propene and oxygen.

The described Showa-Denko process has evolved dynamically for the last two decades. Allyl alcohol obtained in this manner is an intermediate for a new industrial method of the production of glycerol epichlorohydrin. The next installation is used for the chlorination of allyl alcohol to obtain 2,3-dichloro-1-propanol and then the mentioned alcohol is dehydrochlorinated to glycerol epichlorohydrin'.

In 1990 Showa-Denko Corp. started the installation of epichlorohydrin production with the productive capacity of $24000 \mathrm{Mg} / \mathrm{year}$. For this manufacturing capacity the consumption of allyl alcohol is around $17000-18000$ $\mathrm{Mg} /$ year.

Allyl alcohol can be produced with the other methods: by alkaline hydrolysis of allyl acetate or by alcoholysis. In this last case the process is coupled with the production of appropriate alcohol acetate. Usually the reactions of allyl acetate with methanol, ethanol and butanol are used.

There is another method of allyl alcohol production: by epoxidation of propene to propene oxide and then isomerization of propene oxide to allyl alcohol.

Isomerization of propene oxide is carried out at $300^{\circ} \mathrm{C}$ under atmospheric pressure in the presence of lithium phosphate as the catalyst.

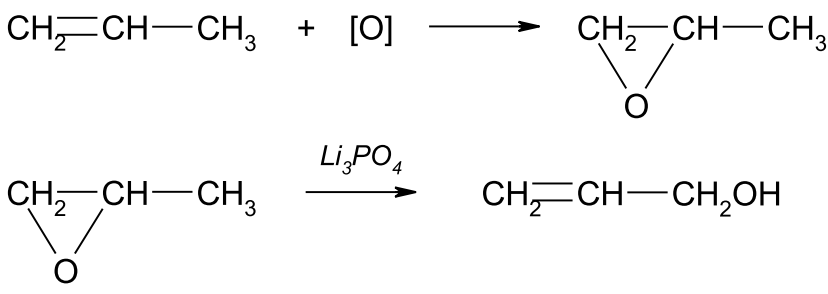

The selectivities of transformation in relation to propene oxide consumed are as follows ( $\mathrm{mol} \%)$ : allyl alcohol 89 , propionaldehyde 6 , acetone 3 , 1-propanol 1 , polymers 1. The conversion of the oxide does not exceed $40 \mathrm{~mol} \%$. Allyl alcohol obtained in this way contains around 0.6 wt $\%$ of 1-propanol, because its separation is too expensive (consumes a lot of energy).

Propene oxide as the main intermediate used in this process is produced on the basis of the latest technologies $^{7,8}$ by direct epoxidation of propene with hydroperoxides of ethylbenzene, tert-butyl or cumene. However, around $40 \%$ of the world's production of propene oxide is obtained by a traditional chlorohydrine method.

\section{Acetoxylation of propene to propene glycol and its acetates}

The next example for using acetoxylation as a competitive method is a relatively new method (developed in the 
90s) of the production of propene oxide by acetoxylation of propene to propene glycol (PG) and its acetates (PGA) and cracking of propylene glycol monoacetates to propylene oxide and acetic acid 9 . The mentioned process can be described with the following reaction equations: mol\% respectively in relation to monoacetates of $\mathrm{PG}$. The conversion of PGA is around $40 \mathrm{~mol} \%$.

Acetoxylation of methyl tert-butyl ether to tert-butyl acetate and methyl acetate

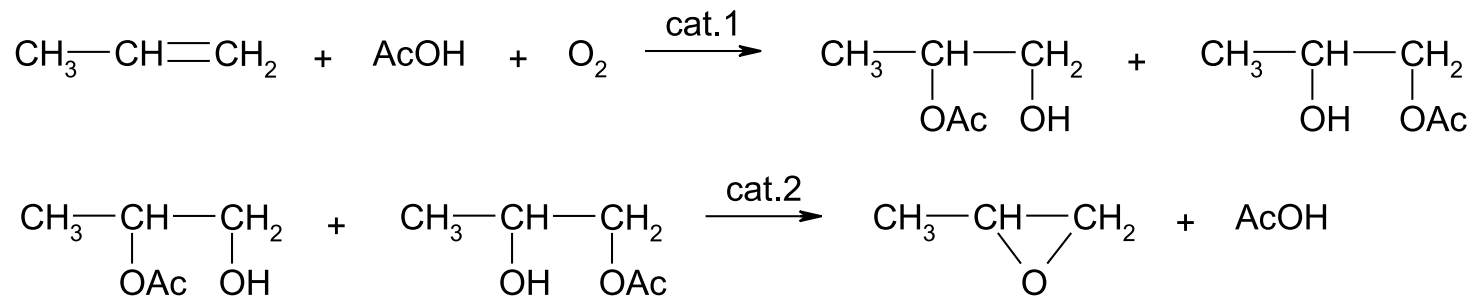

Acetoxylation is carried out in a gaseous phase in the presence of catalyst ( $\mathrm{Pd}, \mathrm{Pd}-\mathrm{Pt}$ and $\mathrm{Rh}$, immobilised on a carrier $-\mathrm{TiO}_{2}, \mathrm{SiO}_{2}$ or activated carbon). Molecular oxygen mixed with acetic and nitric acid $(\mathrm{V})$ is used as an oxidative agent.

Palladium catalysts have high activity and selectivity in the described transformation of propene to propene glycol and glycol acetates (up to $90 \mathrm{~mol} \%$ of selectivity).

Addition of the promoters ( $\mathrm{Pt}, \mathrm{Rh})$ increases the stability and poisoning resistance of palladium catalyst. Cracking of propylene glycol acetates is carried out in a melted potassium acetate used as a catalyst. The optimal process parameters are described in the literature. The optimal parameters for propene oxidation are as folows:

- catalyst: $10 \mathrm{wt} \%$ of $\mathrm{Pd}$ imbedded on activated carbon, - propene to oxygen molar ratio $=1: 3$, temperature $=$ $60^{\circ} \mathrm{C}$; pressure $=0.1 \mathrm{MPa} ; \mathrm{HNO}_{3}$ concentration $=1.7$ $\mathrm{mol} / \mathrm{dm}^{3}$; reaction time $=1 \mathrm{~h}$, catalyst concentration $=$ $53.3 \mathrm{~g} / \mathrm{dm}^{3}$.

The total of the selectivity of acetoxylation of propene to PG and PGA was $90 \mathrm{~mol} \%$ in the described conditions. Optimization of acetate cracking process was not carried out, because this process is very complicated due to the thermal degradation of potassium acetate and acetic acid. The preliminary investigations show that the mentioned cracking should be carried out at the temperature above $400^{\circ} \mathrm{C}$ to achieve a high yield of propene oxide.

Propylene oxide and acetic acid are the main products of cracking of PG and PGA. The maximum yield of propylene oxide and acetic acid is $80 \mathrm{~mol} \%$ and 90
Acetoxylation of MTBE is a new method of the production of tert-butyl acetate and methyl acetate in one technological process. t-Butyl acetate is produced traditionally in the reaction of isobutene with acetic acid, where the excess of acetic acid and high purity of isobutene are necessary. Despite these conditions the substantial amounts of isobutene olygomers, polymers and degradation products are formed.

Frequent cleaning of the reactor and distillation columns (used for the separation of reaction products) is necessary to secure the course of the reaction. Butylene fractions cannot be used in this process because it could result in the formation of a large amount of by-products, thus obtaining the pure t-butyl acetate would be impossible.

In a novel process ${ }^{\mathbf{1 0}} \mathrm{MTBE}$ is used instead of pure isobutene. MTBE is cheaper than isobutene of high purity which results in the reduced costs of the process. MTBE is produced in the reaction of methanol and $\mathrm{C}_{4}$ fraction as a product from catalytic cracking or petrol pyrolysis.

Pure isobutene $(99.9 \%)$ and methanol are obtained during the MTBE cracking process. The direct reaction of MTBE, acetic anhydride and acetic acid in the presence of acidic catalyst is a new technology of t-butyl acetate production. Strongly acidic macroporous resins (e.g. DPT1 or A-36 produced by Rohm\&Haas) were used as the catalysts, but other strongly acidic cation exchangers can be used, too (e.g. sulphonated copolymers of styrene and divinylbenzene). The series of the following reactions in the described process is presented below.

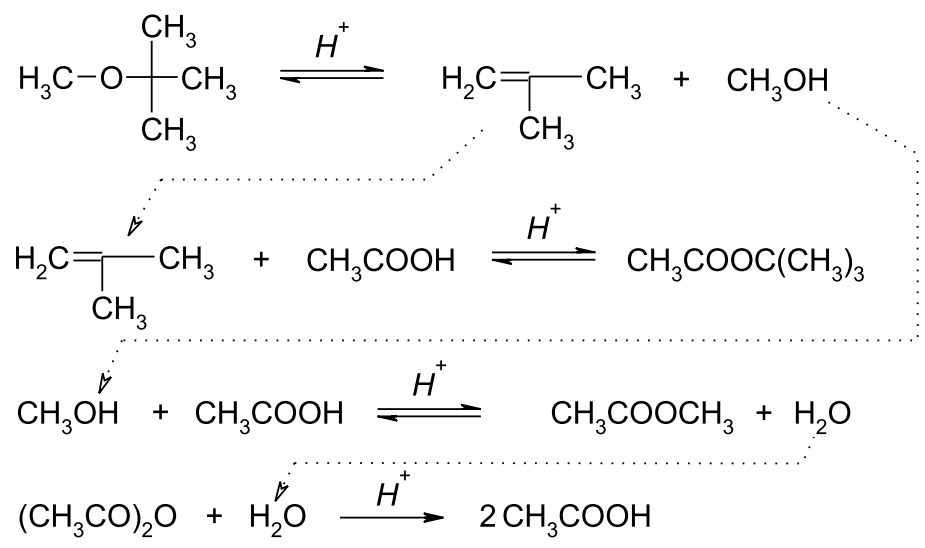<smiles>COC(C)(C)[CH+]COOC(C)(C)OC(C)(C)C</smiles> 
The process is carried out at the temperature of $40-$ $70^{\circ} \mathrm{C}$ under the pressure of $0.1-0.5 \mathrm{MPa}$. The first step is MTBE cracking (1), then the obtained isobutene transforms to t-butyl acetate (2), methanol - to methyl acetate (3) and water reacts with acetic anhydride to acetic acid (4). Summarizing, t-butyl acetate and methyl acetate are formed from MTBE and acetic anhydride.

The described process is conducted in modern installations as the "reactive distillation" with the catalyst imbedded on the plates. The mixture of acetic acid and acetic anhydride is conducted to the top of the reaction column and MTBE to the bottom of the column. Methyl acetate is distilled off from the column and the mixture of tert-butyl acetate and acetic acid is unloaded as tail fraction.

Acetic acid is distilled off from the tail fraction while t-butyl acetates remains as the next tail fraction. Acetic acid is recycled to the reaction column.

A small amount of tert-buthyl alcohol is formed as a byproduct in this process. The formation of $\mathrm{t}-\mathrm{BuOH}$ can be decreased or even eliminated by increasing the amount of acetic anhydride.

The mentioned technique results in the utilization of water in the reaction with acetic anhydride (reaction 4). Direct hydratation of isobutene to tert-butyl alcohol is not proceeded in the described process. However, the formation of tert-butyl alcohol is an effect of partial hydrolysis of tert-butyl acetate.

Forming of isobutene olygomers was substantially reduced in the described novel process of the production of tert-butyl acetate in comparison with the previously used method. It's the result of a low concentration of isobutene in the reaction column. The process is carried out at relatively low temperature. Moreover, the type of catalyst significantly affects the way of olygomerisation. Carrying out the process at $40 \mathrm{oC}$ in the presence of strongly acidic ion-exchange resin DPT-1 results in MTBE conversion of $88.8 \mathrm{wt} \%$ with the selectivity of transformation to tertbuthyl acetate and methyl acetate $79.5 \mathrm{wt} \%$ and $15.0 \mathrm{wt} \%$, respectively.

Using ethyl tert-butyl ether (ETBE) have similar results as described above.

\section{Oxidative acetoxylation of cycloalkenes by hydrogen per- oxide}

The investigations of Mimoun and associates ${ }^{11}$ resulted in the development of a new method of acetoxylation of the alkenes and cycloalkenes in the presence of palladium catalyst and hydrogen peroxide as oxidant. Allyl acetates are formed with high yield using cycloalkenes and alkenes with an unsaturated bond in the middle of the hydrocarbon chain as the substrates in the mentioned method.

The use of alkenes with the unsaturated bond at the end of the chain results in the formation of methyl alkyl ketones. Up to now the best results in the described method were achieved using the catalytic system $\operatorname{Pd}(\mathrm{OAc})_{2}$-benzoquinone. This system turned out to be more efficient than the systems developed earlier (e.g. $\mathrm{Pd}(\mathrm{OAc})_{2}$-benzoquinone- $\mathrm{MnO}_{2}$ or $\left.\mathrm{Pd}(\mathrm{OAc})_{2}-\mathrm{Fe}\left(\mathrm{NO}_{3}\right)_{3}-\mathrm{O}_{2}\right)^{12}{ }^{13}$ due to easier separation of the reaction products and higher activity.

The described process of acetoxylation is universal and can be adapted to many technological applications. The investigations of the process parameters were carried out for the transformation of cyclohexene to 2-cyclohexenyl acetate as presented below:

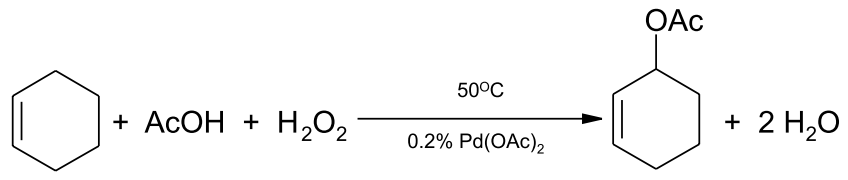

The reaction is carried out in a glass apparatus at atmospheric pressure when hydrogen peroxide $(70 \%)$ is conducted slowly $(2 \mathrm{~h})$ to the solution of $\mathrm{Pd}(\mathrm{OAc})_{2}$ and appropriate alkene in acetic acid.

The total reaction time is $2-12 \mathrm{~h}$ at the temperature of $50^{\circ} \mathrm{C}$ with palladium to cyclohexene molar ratio 1:500. In the described conditions the conversion of cyclohexene is $72 \mathrm{wt} \%$ and the selectivity of transformation to 2cyclohexenyl acetate is $82 \mathrm{wt} \%$. Slow addition of $\mathrm{H}_{2} \mathrm{O}_{2}$ is necessary to minimize the formation of by-products e.g. trans-2-acetoxycyclohexanol.

Trans-2-acetoxycyclohexanol is the result of cyclohexene epoxidation by the peracetic acid formed in situ. Epoxycyclohexane, formed as the intermediate, reacts with acetic acid and opens oxirane ring, which results in the formation of trans-2-acetoxycyclohexanol. Other by-products in the described process are formed in the total amount up to $3 \mathrm{wt} \%$ (e.g. cyclohexen-3-ol, cyclohexen-3on, cyclohexanon). Other examined catalysts $\left(\mathrm{Pd}\left(\mathrm{PPh}_{3}\right)_{4}\right.$, $\mathrm{Pd}\left(\mathrm{PPh}_{3}\right)_{2} \mathrm{Cl}_{2}$ and $\mathrm{Pd}-$ montmorillonite $)$ demonstrated lower efficiency in the described process.

Increasing the concentration of catalyst $\mathrm{Pd}(\mathrm{OAc})_{2}$ results in the decrease of the cyclohexene epoxidation reaction, thus the selectivity of the transformation to 2-cyclohexenyl acetate increases significantly. The conversion of cyclohexene increases moderately as well.

Hydrogen peroxide is slowly introduced to the reaction mixture of cyclohexene, acetic acid and palladium acetate in order to regenerate the catalyst continuously. The regeneration of the catalyst goes in the reaction of Pd (0) oxidation to Pd (II), thus Pd (0) residue is not formed and epoxidation of cyclohexene is inhibited, so the amount of the by-products is significantly reduced.

Using $70 \% \mathrm{H}_{2} \mathrm{O}_{2}$ in place of the $30 \%$ one enables keeping the reaction mixture homogenous. The introduction of 1,4-benzoquinone as a cocatalyst increases the selectivity of the transformation to 2-cyclohexenyl acetate from 10 to $30 \mathrm{wt} \%$. Moreover, the conversion of cyclohexene is increased, too. In order to achieve high selectivity of the transformation and cyclohexene conversion it is necessary to keep the high molar ratio of palladium acetate to cyclohexene.

Under the following conditions: $\mathrm{Pd}(\mathrm{OAc})_{2}$ / cyclohexene molar ratio $=1 / 1000 ; 1,4$-benzoquinone $/$ cyclohexene molar ratio $=20 / 1$ with the rest of the parameters as described above, the conversion of cyclohexene is $80 \mathrm{wt} \%$ and the selectivity of transformation to 2cyclohexenyl acetate is $93 \mathrm{wt} \%$.

Other alkenes can be processed in this way, but it is necessary to increase the concentration of the catalyst in order to achieve the satisfactory values of the selectivity and conversion (molar ratio of $\mathrm{Pd}(\mathrm{OAc})_{2} /$ alkene $=1 /$ 500 or lower). Similar results can be achieved using cyclopentene, cycloheptene and cyclododecene as a 
substrate. Under the similar technological conditions terminal alkenes as 1-hexene and 1-octene react to form methyl butyl ketone and metyl hexyl ketone respectively.

\section{Hydroxylation of butadiene}

Mitsubushi Kasei Corporation developed and industrialized the novel process of the production of 1,4-butanediol and tetrahydrofuran from 1,3-butadiene ${ }^{14}$. The most important reaction of this process was diacetoxylation of 1,3butadiene to form 1,4-diacetoxyl-2-butene (1,4-DAB) using a novel catalytic system of $\mathrm{Pd} / \mathrm{Te}$ on carbon under mild conditions. Many catalytic systems were examined in this reaction and the most efficient system was palladium on carbon with an addition of tellurium, which markedly improved the catalytic performance. The selectivity of the transformation of 1,3-butadiene to 1,4-DAB was $93 \mathrm{~mol} \%$ at the temperature of $85^{\circ} \mathrm{C}$, the molar ratio of butadiene to oxygen $=1: 1$ and butadiene to acetic acid molar ratio $=1: 4$.

The next stages of the process were as follows: hydrogenation of 1,4-DAB to diacetoxybutane, hydrolysis to acetoxybutanol and butanediol and THF formation. Today in Japan about 20000 ton/year of 1,4-butanediol and THF are produced using the method described above.

\section{Acetoxylation of isobutene and 1,3-butadiene}

A novel process of acetoxylation has been described ${ }^{15}$. The gaseous mixture of isobutene and 1,3-butadiene was contacted with acetic acid to obtain acetic acid C4-esters. The mixed stream used as a feedstock in the described process is a by-product of naphtha steam cracking comprising isobutene $(25-30 \mathrm{vol} \%), 1,3$-butadiene $(40-50$ vol\%) and other compounds in smaller quantities viz. isobutane $(1-2 \mathrm{vol} \%)$, n-butane $(2-4 \mathrm{vol} \%)$, 1-butene $(8-10 \mathrm{vol} \%)$, 2-butene (5 - $10 \mathrm{vol} \%), 1,2$-butadiene $(0-2$ vol\%), propadiene $(0-1 \%)$ etc. The composition of the feedstock is varying and depends on many factors e.g. naphtha composition and cracker operating conditions. The $\mathrm{C} 4$ stream is reacted with acetic acid in additional reactor e.g. fixed bed, fluidized bed, trickle bed, slurry, bus loop etc. The reaction is carried out at the temperature of 40 to $90^{\circ} \mathrm{C}$ in the presence of acidic catalysts such as zeolites and strong acid ion-exchange resins.

The addition of water is preferred in the described method in the amount of 0.5 to $20 \mathrm{wt} \%$ in relation to the total charge of the reactor. Additionally, polymerization inhibitors were added to the reaction mixture. The product stream comprises mainly n-butenyl acetate, sec-butenyl acetate and t-butyl acetate and the unreacted $\mathrm{C} 4$ substrates, which can be separated and recycled to the reactor. Esters obtained in the product stream can be separated by azeotropic separative methods. These acetates are the valuable products for the organic industry.

\section{Gas phase acetoxylation of toluene}

Direct synthesis of benzyl acetate over Pd-containing catalysts has been described ${ }^{16,17}$ as the novel and environmental friendly process. The conventional chlorine method for the production of benzyl acetate produces significant amounts of harmful by-products (e.g. $\mathrm{HCl}$ ) and has several stages: 1) chlorination of toluene to chlorotoluene, 2) hydrolysis of chlorotoluene to benzyl alcohol and 3) esterification of benzyl alcohol to benzyl acetate.
The described novel method is a single-step low-waste process illustrated below and gives a very valuable product for the modern chemical technology.

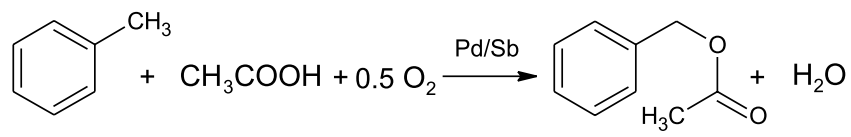

Pd-Sb catalyst supported on the anatase was used in this process. The reaction conditions were as follows: temperature of $210^{\circ} \mathrm{C}$, gauge pressure of $2 \mathrm{bar}$, molar ratios of substrates: toluene/acetic acid/oxygen/inert gas $=1 / 4$ / $3 / 16$, contact time $=1.34 \mathrm{~s}$.

Many experiments were conducted to research the synergistic effects between Pd and Sb in bimetallic catalysts useful in the described process. Similarly, the influence of the temperature, contact time and the molar ratio of the substrates were investigated to obtain the optimal process parameters. The described process is unquestionably one of the green and low-waste chemical technologies, very important and ready to implement for the industrial applications.

\section{THE ACETOXYLATION CATALYSTS}

It was presented in the above described processes that the catalyst is the necessary and essential element in every acetoxylation reaction. Detailed characterization of the acetoxylation catalyst can be found in literature ${ }^{\mathbf{1 8}, 19}$. However, the general information about the catalysts applied for the acetoxylation should be briefly presented.

Palladium and its salts or complexes is usually used as the best acetoxylation catalyst. Depending on the method of acetoxylation and the type of the reactor used in this process, heterogeneous or homogenous catalyst can be applied. Palladium on the support (viz. $\mathrm{TiO}_{2}, \mathrm{SiO}_{2}$, activated carbon) is the most frequently used heterogeneous catalyst for this reaction. For the reaction conducted in the liquid phase, palladium acetate or palladium salts can be applied to the reaction mixture as the homogenous catalysts. Also the beta-zeolite or heteropolyacids can be applied as the catalysts for the acetoxylation (e.g. monoterpenes acetoxylation presented in literature ${ }^{20,21}$ )

Addition of the second metallic compound to the palladium catalyst often increases the selectivity of the transformation to the desired products ${ }^{16}$. Moreover, the second compound is often necessary as the reversible oxidant in the reaction system. Complexes of $\mathrm{Cu}(\mathrm{II}), \mathrm{Fe}(\mathrm{II})$, heteropoly acids and benzoquinone are commonly used as reversible oxidants in these systems. The role of the reoxidant has been described in detail in the literature ${ }^{18}$. It follows from literature that palladium can be applied as the catalyst in the form of the Pd-561 giant clusters ${ }^{19}$. The molecule of Pd-561 cluster consists of a positively charged metal core containing 561 dense-packed Pd atoms (in the form of an idealized five-shall icosahedron or cuboctahedron-shaped core), $\approx 60$ neutral L ligands (phen or bpy), which are bound to the surface of the metal core, and $\approx 180$ outer-sphere $\mathrm{OAc}^{-}$anions which compensate the positive charge of the metal core. These Pd species have good catalytic activity, high selectivity in the synthesis of allyl organic compounds and they are active at lower temperatures in comparison to the other commercial Pd metallic catalysts. 


\section{CONCLUSIONS}

The described acetoxylation processes are part of the novel technologies, introduced to the industry in the last years and intensively explored or developed and prepared for practical applications. Moreover, the mentioned processes are numbered among the low-waste, efficient and environmental friendly technologies. It is a result of a few factors: high selectivity of transformation to the desired products and processing a few chemical reactions in one reactor or in one process. The described processes create new alternatives and competitive methods of the production of the known and useful intermediates and final products.

\section{LITERATURE CITED}

1. Kirk-Othmer (2004). Encyclopedia of Chemical Technology. Fifth Edition, Vol.2, pp.234 - 242. London: Wiley Interscience.

2. Collective work (1989). New processes of organic synthesis. Moscow: Chimija.

3. Bijsterbosch, J.W., Das, A. \& Kerkhof, F.P.J.M. (1994) Clean technology in the production of epichlorohydrin. $J$. Cleaner Prod. $2(3$ - 4), 181 - 184. DOI: 10.1016/09596526(94)90041-8.

4. Lindsay, F.K., Grange, L. \& Willey, B.F. (1944). US Patent No. 2,345,134. Washington D.C.: U.S. Patent and Trademark Office.

5. Sano, K., Maki, K. \& Kamei H. (1991) US Patent No. 5,011,980. Washington D.C.: U.S. Patent and Trademark Office.

6. Hiro, T., Sakurai, K. (2004). US Patent No. 6,743,955. Washington D.C.: U.S. Patent and Trademark Office.

7. Lewandowski, G. \& Milchert, E. (2000). Integrated production of propylene oxide, phenol and acetone. Przem. Chem. 79, 410 - 411.

8. Milchert, E. (1994). Hydrogen peroxide method of the propylene oxide production. Przem. Chem. 73, 11 - 13 .

9. Gusevskaya, E.V., Karandin, A.V., Likholobov, V.A., Kondratiev, A.V. \& Markevitch, V.S. (1993). Propylene oxide synthesis via propene acetoxylation over supported palladium and platinum catalysts followed by cracking of glycol acetates in a melt of potassium acetale, Applied Cat. A: General 97(1), 1 - 15. DOI: 10.1016/0926-860X(93)80062-U.

10. Murphy, C.D. \& Warner R.J. (2003). US Patent No. 6,593,491 B2. Washington D.C.: U.S. Patent and Trademark Office.

11. Jia, H.Ch., Miller, P. \& Mimoun, H. (1995). Palladiumcatalyzed allylic acetoxylation of olefins using hydrogen peroxide as oxidant. J.Mol.Cat. A: Chemical 101, 127 - 136. DOI: 10.1016/1381-1169(95)00063-1.

12. Hansson, S., Heumann, T.R. \& Akermark B. (1990). Preparation of allylic acetates from simple alkenes by palladium(II)-catalyzed acetoxylation. J.Org.Chem. 55, 975 984. DOI: $10.1021 /$ jo00290a031.

13. Akermark, B. \& Larsson, E.M. (1993). A catalytic system for allylic acetoxylation consisting of palladium(II) and nitrate and using oxygen as final oxidant. Tetrahedron Lett. 34, 2523 - 2526. DOI: 10.1016/S0040-4039(00)60458-6.

14. Schunk, A., Baltes C. \& Klein J. (2005). How high throughput technology can facilitate better hydrocarbon processing. Oil Gas Eur. Mag. 31, 77 - 83.

15. Gracey, B.P. \& Hazel, N.J. (2005). US Patent No. 6,949,671. Washington D.C.: U.S. Patent and Trademark Office.

16. Benhmid, A., Narayana Kalevaru, V., Martin, A., Lucke, B. \& Pohl M.M. (2006). Direct synthesis of benzyl acetate and optimisation of reaction conditions for the gas phase acetoxylation of toluene. Cat. Today 112, 192 - 196. DOI:10.1016/ j.cattod.2005.11.041.
17. Narayana Kalevaru, V., Benhmid, A., Radnik, J., Pohl, M.M., Lucke, B. \& Martin A. (2009). Palladium-catalysed vapour phase aerobic acetoxylation of toluene to benzyl acetate. Cat. Today 141, 317 - 324. DOI:10.1016/ j.cattod.2008.06.004.

18. Gusevskaya, E.V. (2003). Organometallic catalysis: some contributions to organic synthesis. Quim. Nova 26(2), 242 248. DOI: $10.1590 / \mathrm{S} 0100-40422003000200017$.

19. Moiseev, I.I. \& Vargaftik, M.N. (2004). Allylic oxidation of alkenes with palladium catalysts. Coord. Chem. Rev. 248, 2381 - 2391. DOI: 10.1016/j.ccr.2004.05.020.

20. Da Silva, K.A., Kozhevnikov, I.V. \& Gusevskaya, E.V. (2003). Hydration and acetoxylation of camphene catalyzed by heteropoly acid. J. Mol. Cat. A: Chemical 192, 129 - 134. DOI: 10.1016/S1381-1169(02)00417-X.

21. Castanheiro, J.E., Fonseca, I.M., Ramos, A.M. \& Vital, J. (2008). Acetoxylation of camphene catalyzed by beta zeolite. Cat. Comm. 9, 2205 - 2208. DOI: 10.1016/j.catcom.2008.05. 009.492. DOI: 10.1016/j.chemoExperiment. Nanosci. 4, 121 137. DOI: $10.1080 / 17458080902929945$. 